\section{AN ETHICAL METHOD FOR DEVELOPING ELECTRONIC VOTING SYSTEMS}

\section{Michael Bowern ${ }^{1}$}

\begin{abstract}
Recently there has been widespread concern about the use of electronic voting machines to record votes in elections. Although discussions on this technology have taken place in several countries, this paper will focus on the issues raised in the context of the USA presidential elections in 2000 and 2004. These concerns will be considered in the light of practices in Australia.
\end{abstract}

This paper describes these areas of concern, and comments on some of the proposals coming from the USA, described as "best practices", to remedy the problems of voting technology and electoral processes. The paper argues that the processes used to develop voting systems should also be considered, and that a method called Value Sensitive Design (VSD) should be used as part of the development activities. This is to ensure that human values are identified and incorporated in the design, and trust is engendered in the systems and in those who develop them.

\section{Introduction}

Recently there has been widespread concern about the use of electronic voting machines to record votes in elections. Although discussions on this technology have taken place in several countries, this

\footnotetext{
${ }^{1}$ Centre for Applied Philosophy and Public Ethics Charles Sturt University, Australia
}

paper will focus on the issues raised in the context of the presidential and other elections in the USA. These concerns will be considered in light of practices in Australia.

The concerns in the USA, and the associated activities to raise public awareness of these concerns, have been addressed at the grass roots level (eg Verified Voting Foundation, 2004); at the academic level (e.g. a workshop at the Kennedy School of Government, 2004); and by other research at the Massachusetts Institute of Technology (Selker, 2004). The concerns cover not only the technology used for voting and vote counting, but also the processes for acquiring the technology, for registering voters, and for conducting the elections.

This paper describes these areas of concern, and comments on some of the proposals coming from the USA, described as "best practices", to remedy the problems of voting technology and electoral processes. The paper argues that the processes used to develop voting systems should also be considered, and that a method called Value Sensitive Design (VSD) should be used as part of the development process. This is to ensure that human values are identified and incorporated in the design, and trust is engendered in the systems and in those who develop them.

\section{Voting systems outline}

There are a number of basic components of voting systems, regardless of the use of a particular technology. Figure 1 shows these components. 


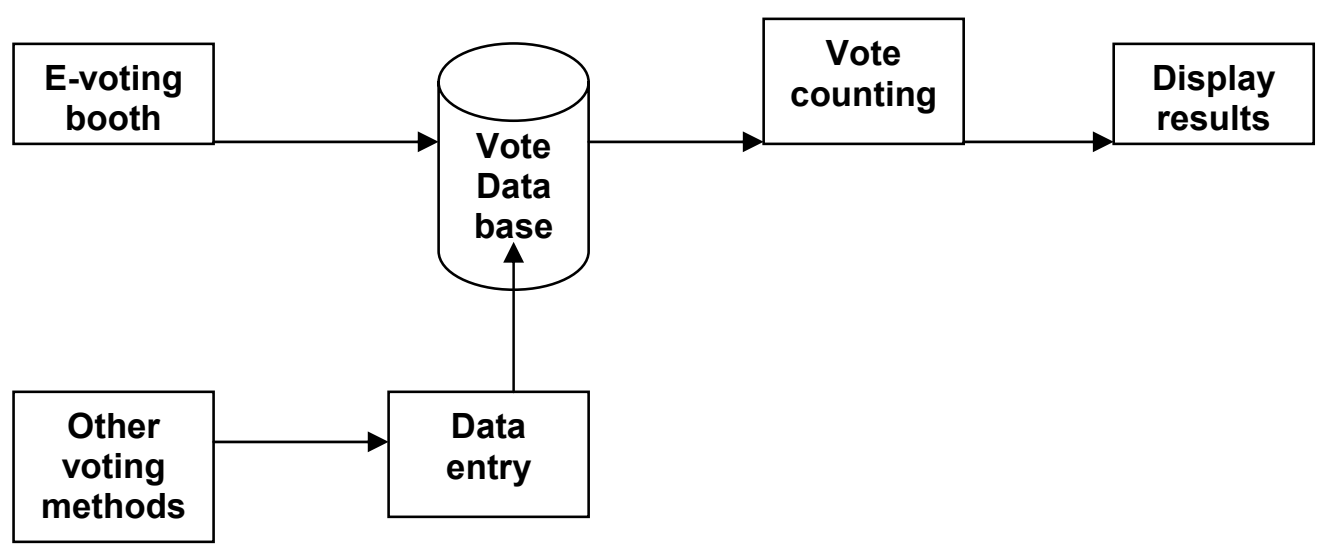

Figure 1: Simple voting system components

An e-voting booth is the place where voters cast their vote using some form of electronic voting machine. In the USA, touch screens are a common method to capture the ballot, but other forms of interface, such as a simple keypad, are also possible. Normally paper is not used, and the ballots are transferred to a vote database, either via a network, or by the use of magnetic media, e.g. a CD-ROM.

At present other, non-electronic, methods of casting a vote are used in many places, in conjunction with electronic voting. These methods includes: mechanical or electro-mechanical means, e.g. punched cards; marking special ballot paper which can be read automatically; and the traditional method of marking a ballot by hand. A postal ballot also uses one of these methods.

For these non-electronic voting methods some form of data entry is required to convert the ballots to electronic records for storing on the vote database. Data entry methods include: mechanical means of reading punched card ballots; optical methods of reading mark-sense ballot papers; and the keying in of traditional ballots.

When the polling is closed and all ballots are on the database, vote counting can take place. This is done by computer software which counts the records on the vote database, and allocates preferences if required. Manual counting of paper ballots can also be used, and this method has been suggested as a way to validate a ballot in dispute.

Finally, some method to display the results of the election is needed, and there are several methods to do this. Electronic means for publishing in the print and TV media and via the Internet are becoming more common.

Allied to this basic system there are ways to register voters, to prepare the ballots, to provide security regarding ballots, both paper and electronic, before and after votes are cast and then counted; and there are a number of audit and assurance activities for 
both the electoral processes and the voting technology used.

Clearly, in a system as complex as this there are many opportunities for equipment and process failure, and for people to corrupt the process and/or pervert the results of an election.

\section{A summary of the problems in the USA}

During the USA presidential election in 2000, a substantial number of problems occurred with some of the technology used by citizens to cast their vote. Many of these problems were with mechanical (lever operated) and electro-mechanical systems to record votes in various forms of punched cards. There were also problems with electronic voting systems, some using touch screens. As a result of these problems, the US Congress identified a number of initiatives to modernise and improve the election processes, and the Helping America Vote Act (HAVA) was passed in October 2002. One requirement of this Act was the replacement of old voting technology with electronic voting systems, also known as direct-recordingelectronic (DRE) systems, which typically do not produce a paper record of the ballot.

During the year 2004, a number of organisations were formed in the USA to protest against the use of some models of electronic voting systems in the presidential elections to be held in November 2004, and to take action to ensure the integrity of that election process.

The "Computer Ate My Vote" Day of Action was held in July 2004 to coincide with the National Academy of Sciences hearing on voting systems. Rallies were held in 18 states to draw the public's attention to the issues. During this event, election officials were asked to pledge to count all votes and to adopt voting machines that produce a paper record of the vote.

The rallies were co-ordinated by the Verified Voting Foundation, which also sponsored and organised the TechWatch programme, to enlist technology professionals to volunteer to observe and document problems which arose with the election process and voting technology during the November elections. This documentation would be used to provide evidence to support litigation and policy making with respect to electronic voting. Both events were strongly supported by the Computer Professionals for Social Responsibility, and many other like-minded organisations. Before November 2004, over 1400 technologists had registered to support this activity. By early December, over 38,000 election incidents had been reported (Verified Voting Foundation, 2004). Incidents have been reported from every state, and cover a range of issues, not all related to voting technology. In fact, the majority of incidents reported were about voter registration problems and difficulties in being able to vote, often because of insufficient polling places and paper ballots to meet the voter turnout.

A main area of concern is the use of electronic voting machines, which have a history of malfunction, resulting in lost votes, or votes cast for a candidate not chosen by the voter. There is a concern that some of these malfunctions result from tampering with the equipment or other corrupt practices.

A solution proposed by several of the groups of concerned people, and some state legislatures, is the use of a voter verifiable 
paper trail, also know as a voter-verified paper ballot, which provides a permanent paper record of each voter's intention. This enables the voter to check that their ballot shows their voting intention, usually by reading it, before the vote is finally cast. There are several methods available to produce a paper version of the vote. The paper votes can also be used if a manual count is required, and/or for audit purposes.

The requirement for a paper record of each vote seems to defeat the purpose of using electronic voting machines. Also, it has been shown that the manual counting of votes is less accurate than electronic counting by proven software. Thus, proponents of paper records seem to be suggesting that they will accept inaccuracies in manual counting, as they have done for years, if this method is used to verify a vote. However, they will not accept inaccuracies in voting machines, which is, of course, the correct position to take. As this paper shows, there are many instances of failure in voting machines, but vote verification using 'a paper record of each vote and manual counting is not the remedy.

Selker (2004) also argues against a paper record, and proposes an audit trail using an audio record to provide voter verification and a record of the votes.

\section{Electronic voting best practices}

A symposium held at Harvard University (Kennedy School of Government, 2004) identified six major themes deriving from issues related to voting and vote counting in the USA. The symposium was held in June 2004, the timing of which reflected the growing concern in the wider community of problems with the current state of voting processes, particularly with respect to electronic voting. In the terms of the report, the six themes are shown below. Each theme includes a number of points, describing the "best practices" identified by the symposium.

\section{Theme 1: Certain immediate steps must be taken.}

This theme particularly focuses on the, then, forthcoming USA presidential election and the first point covers the development of open standards, testing and certification processes for electronic voting technology. The second point covers the need for technology experts to be made available to voting officials, particularly in the area of equipment purchases, and the need for truly independent auditing organisations.

\section{Theme 2: A hybrid of paper and electronic systems provides an effective voting system.}

Of the five points in this theme, two points cover the issues of "electronic interfaces" between the voter and the voting machine, to support customisation of the ballot and accessibility; and another two points stress the perceived need for a paper ballot for voter verification and an audit trail. The final point covers the benefits of hybrid systems, using several different types of equipment, to provide flexibility in the voting processes; for example, in the case of equipment failure. 
Theme 3: The process is as important as the underlying technology.

This refers to the voting process, and the first four points address the poll workers and election officials. They cover the need for training, especially with the voting equipment; education to ensure that the officials and workers have the public trust; the selection of poll workers to ensure that they are competent, motivated and responsible; and ways to ensure that there is no reliance on vendors in the event of failure of the voting equipment. Another four points cover: aspects of the process to deliver the official result of the election, and address the need for sufficient time to determine the final result; the trade off between speed and accuracy in this process; a method of provisional voting for voters whose eligibility to register is queried; and improved methods of voter verification.

\section{Theme 4: Good voting systems require good design standards.}

These design standards cover the need for: a variety of voting interfaces; equipment design that ensures that the voter knows when an equipment failure occurs; a full range of accessibility features; and high standards of testing for security, usability and reliability.
Theme 5: Transparency builds public trust and supports legitimate elections.

The first of these points covers the need for access, preferably by the public, to the software and other aspects of voting systems or, alternatively, access by the wider ICT security community. Secondly, ultimately there should be full public disclosure of all security issues; but perhaps this disclosure could be delayed to allow the vendors to fix their problems. The final two points cover the voting technology acquisition process. There is the need for this process to be open to public scrutiny. Also, this openness should provide a way for jurisdictions to learn from the experiences and knowledge of each other, to minimise the risk of imprudent and risky acquisition decisions.

\section{Theme 6: Election systems must have built-in auditing capability.}

There are five points in this theme, covering aspects of auditing the system and technology and the voting process to provide assurance that the vote that is cast is the vote that is counted. Firstly, the reconciliation process must be open and fully understood and accepted by all parties. Any disputes should be about how the process was conducted, rather than the process itself. Next, there should be a verifiable audit trail that covers the life of a vote, from when it is cast to when it is counted, to ensure that votes cannot be added, changed or 
deleted. The third point requires a court supervised manual recount in the event of an identified voting irregularity. Fourthly, the auditing process should exclude the involvement of the vendor of the system. Finally, the reconciliation audit, covering the outcome of the ballot, should be complementary to a full testing process covering the whole system.

\section{Discussion on these practices}

This catalogue of practices is a good starting point for defining the requirements of all voting systems but, understandingly, it is very much focussed on the beliefs, practices, needs and shortcomings of the elections in the USA.

Many of these proposed practices are already in place in other countries, including Australia, Brazil and India. The following discussion on some of the practices described above compares the Australian experience with that of the USA.

The nature of Australia's election laws and electoral systems means that well established processes and practices must be in place to ensure the smooth running of elections. In addition, while the USA has a simple "first past the post" system of voting, Australia has proportional and preferential voting systems, which add complications to the solutions recommended by the Harvard workshop, as described below.

\section{Voter registration and the opportunity to vote}

The Election Incident Reporting System (Verified Voting Foundation, 2004) recorded over 38,000 incidents during and after the elections in November 2004. Many of these incidents point to an inadequate voter registration system, covering absentee and provisional ballots, issues of voter identification and criminal status problems.

Other incidents indicate a lack of planning for a higher than expected voter turn out, and inadequate practices by untrained or uncommitted polling place officials. These incidents included: late opening and/or early closing of polling places; long queues of voters, some not being allowed to vote; an insufficient number of ballot papers; and poor access and support for people with disabilities and those with insufficient English language skills.

In Australia, since 1924, it has been compulsory for every citizen of voting age to vote in an election. To support this requirement there is an electoral roll for each jurisdiction, and it is compulsory for citizens to enrol to vote when they reach 18 years of age. Therefore, maintaining a roll of registered voters is an ongoing process.

Because of the compulsion to vote, Australian election systems must have the capacity to enable every eligible person to vote, usually on a polling day, but also via postal voting, or pre-polling.

\section{Independent electoral officials}

In a report in the Washington Post (Carter, 2004), former president Jimmy Carter commented on the work done by a bipartisan commission, led by him and former president Gerald Ford, to recommend changes to the American electoral process. (The recommendations resulted in the Help America Vote Act of 
October 2002.) Carter commented on the need for:

A non-partisan electoral commission or a trusted and non-partisan official who will be responsible for organizing and conducting the electoral process before, during and after the actual voting takes place.

He went on to say that:

Florida voting officials have proved to be highly partisan, brazenly violating a basic need for an unbiased and universally trusted authority to manage all elements of the electoral process.

And:

Four years ago, the top election official, Florida Secretary of State Katherine Harris, was also the cochair of the Bush-Cheney state campaign committee. The same strong bias has become evident in her successor, Glenda Hood, who was a highly partisan elector for George W. Bush in 2000.

It is likely that there are examples of this type of partisanship in other states.

By way of contrast, since 1902 Australia has had its federal elections run by public officials. It now has independent electoral commissions covering federal, state and territory elections, staffed by public servants, and supported by temporary polling officials who are employed and trained to support each election.

\section{Vote verification}

A practice advocated in the report is the use of a paper ballot, to provide a verifiable vote and the ability to audit a disputed result, and an electronic method to read the ballot for counting. Optical character recognition (OCR) is suggested for the reading mechanism, and although not mentioned, this could include optical mark reading (OMR). Another method is the production of a paper record of the vote cast by other electronic means.

Potential issues with these methods include:

Errors caused by citizens who do not record their vote in a readable way on the ballot paper which is to be read by OCR or OMR;

Errors in machine reading of the paperballots;

Producing a machine-readable paper record from an electronic voting machine;

Errors in reading the paper records from 3 ;

If 3 is not possible, modifying electronic voting machines to include a printer interface; and

Errors in counting ballots by manual means, if that is required, e.g. for vote reconciliation.

The six points above relate to "first past the post" voting. If Australia were to follow the proposed practices, there would be additional issues related to the Australian electoral systems, including:

Problems in the design of OCR or OMR ballot papers to cover 
the proportional and preferential voting models;

Problems for some voters to mark their ballot in a machine readable way;

Point 2 would be particularly valid in Tasmania and the Australian Capital Territory (ACT) which use the HareClark electoral system, with preferential voting for multiple candidate electorates (ACTEC 2004a); and

The additional design problems and additional cost for Tasmania and the ACT to produce multiple versions of the ballots papers using the Robson Rotation, a method of presenting candidates names on the ballot papers in many different orders, to minimise the effect of the so-called "donkey vote" (ACTEC 2004b).

\section{The development process for voting systems}

A shortcoming of the catalogue of best practices is that it has scant coverage of the processes to develop voting machines and systems, and the practices of the companies that make them.

The first point of Theme 5 does strongly cover the requirement for source code to be openly available, stating:

Restrictive intellectual property practices which prevent code review are unacceptable in the realm of voting.
And:

Non-disclosure agreements have no role in [the] realm of voting.

Also, point one of Theme 1 identifies the need for open standards for voting systems and voting processes, and for testing and certification processes. These standards are seen as an aid to ensuring "a competitive market and thus responsive vendors", and as a "help with popular perceptions of trust."

Perhaps ensuring a competitive market is part of the problem facing the USA legislatures. Miller (2004) cites examples of conflicts of interest where senior executives of the four main companies manufacturing electronic voting equipment are major donors to the two main political parties, and some are fund raisers for the Republican Party. There have also been some very close links between senior electoral and other state officials and these companies, described by Miller as "a revolving door between elected officials and the voting machine companies..."

\section{The Canberra experience}

It is possible to provide reliable, accurate, secure and trustworthy electronic voting systems, as has been proved in Australia, since 2001. The Australian Capital Territory (ACT) has a reliable system that does not need to keep a paper copy of each vote. The system, known as eVACS (electronic voting and counting system) was developed by a local company in Canberra. The ACT has one of the most complex voting systems in the world, with: multiple candidate electorates; rotation of candidates names on the ballot paper to minimise the so called "donkey vote"; and preferential voting using the Hare-Clark system of proportional representation. 
Electronic votes are cast using a standard PC and keypad connected to a secure local network. Only the election software is installed on the PC, operating in a Linux environment. The source code of the system is available for inspection by anyone, and is audited by an independent third party.

Voters navigate around the ballot paper using the keypad, and select their candidates in their order of preference. Changes can be made to this order at any time, and when the voter is finished they are required to confirm their selection before submitting the vote. Informal voting (i.e. not casting a vote) is possible. Visually impaired voters, or those with poor reading skills, can vote in private through the use of an audio function; and on-screen voting instructions are provided in English and eleven other languages. There is a range of back up and security functions to ensure the reliability and integrity of the system, including keeping a record of every keystroke. The keystrokes and the back up of other data provide a complete audit trail and recovery mechanism in the event of failure. There is no way to link a voter to the vote they have cast.

\section{A matter of trust}

Clearly there is a serious lack of trust in the technology and processes of the USA election system. The current main focus of this lack of trust is on the problems associated with voting machines using touch screen technology. However, there are other sources of discontent, dating back to the 2000 elections, when there were many reports related to the malfunction of mechanical voting machines. These problems were attributed to lack of maintenance of the machines, some of which had been in service for many years.
For citizens to be disenfranchised because voting machines were not maintained is a serious state of affairs. In some places, these mechanical devices have been replaced by electronic voting machines, including some using touch screen technology. Regardless of the type of technology in use, the demand for a paper record shows a serious lack of trust in voting technology.

Friedman et al (2000) discuss the nature of trust in an on-line environment, and many of their examples and arguments can be applied to voting systems, even if they do not operate on-line. A major thrust of their argument is that "people trust people, not technology", and they prefer not to use the common meaning of trust when it is applied to systems performing as specified, and meeting other attributes and requirements covering safety, reliability, security, etc.

To support this point they use the example of a building which is professionally constructed to meet the current earthquake standards. If the building is destroyed because it is hit by an extreme earthquake, well beyond that covered by the building standards, then trust in the construction engineers is not denied, because protecting the building and its occupants from that level of harm was beyond the engineers' control.

In other words, our trust in the designers of technology (or technological artifacts) is bounded by our understanding of the conditions under which the technology functions reliably and safely. (Friedman et al 2000).

For citizens to trust the designers and developers of voting systems and 
technology they need to understand what is within the control of these engineers. This control will be provided by the use of standards, methods and processes for requirements acquisition, design, development, testing, installation, and ongoing operation, support and maintenance. Within the control of the developers there is: the electronic voting technology and systems; the range of people involved in the development of the technology and systems; and the development processes.

Outside the control of the developers, and still requiring the trust of citizens are: the electoral officials who manage and control the election process; the poll workers, who help to run the election; and the candidates, and their party and support organisations.

It should be noted that technology, if it is trusted, can be used to identify some corrupt activities by these people.

\section{Voting in the future}

The use of technology to support democratic processes is understandable and inevitable. However, as discussed, the problems mentioned above are not so much about the technology itself, as they are about the processes used to acquire, design, develop, operate and maintain voting systems.

It has been predicted that with the advent of the Internet and other aspects of information and communications technology (ICT) there will be much greater use of this technology in our democratic processes, especially voting, regardless of the model of democracy used. Citizens are likely to be using electronic voting systems to select a representative, to make decisions, and/or to vote for legislation or regulations. Whatever the reason for voting, every citizen must fully trust the technologists developing the systems and equipment to support the voting process, or they cannot have faith in the outcome of the vote. The processes that are mainly used now for developing voting software and systems may not be adequate for this new democratic environment.

\section{Value sensitive design}

In recent years, a number of methods have been developed to include the ethical aspects of software and systems development. Although there has been substantial research and interest in the development of information systems which support human values, Friedman et al (2003) consider this as being piecemeal. They have identified the need for an overarching method to handle the value dimensions of design work. They consider that Value Sensitive Design (VSD) to be such a method.

This method approaches the design of a system to include human values from three perspectives, by applying conceptual, empirical and technical investigations into the requirements and other aspects of the system. These investigations are employed iteratively.

Conceptual investigations include: consideration of stakeholders, classified as direct and indirect; identification of the values associated with the system; and consideration of the trade-offs, if any, among competing values in the design, implementation and use of the system.

Empirical investigations extend the conceptual investigations, particularly in the human context, but also cover organisational aspects. Potentially, empirical investigations can use the entire 
range of social science research quantitative and qualitative methods.

Technical investigations cover two main areas. Firstly, they consider how the existing properties of the technology support or hinder human values. The second area covers the design of systems to support the identified values using the technology or its underlying properties.

The paper also includes ten practical suggestions, which initially seem to be a sort of outline procedure on how to use VSD, with these points mainly focussing on aspects of the conceptual investigation. The ten points are:

Start with a Value, Technology or Context of use.

Identify direct and indirect stakeholders.

Identify benefits and harms for each stakeholder group.

Map benefits and harms onto corresponding values.

Conduct a Conceptual investigation of key values.

Identify potential value conflicts.

Integrate considerations into one's organisational structure.

Human Values (with ethical import) often implicated in system design.

Heuristics for interviewing stakeholders.
Heuristics for Technical investigations.

The conclusion to the paper by Friedman et al (2003) encourages other researchers and designers to "critically examine, use and extend" the VSD approach. So the following two sections consider how VSD might be applied to the system development lifecycle. Section 11 considers the application of VSD in the development of an electronic voting system.

\section{Life cycle application of VSD}

By its title, Value Sensitive Design purports to be a design method and, from an engineer's or system developer's point of view, it would typically be a tool to be used in the design phase of the development life cycle. However, the comment that VSD is an iterative methodology applies not only to its use in the design phase, but also to other stages of the development life cycle.

So the method would also have application in the feasibility and requirements analysis stages of a project. Findings of the three types of investigation could inform a feasibility report, thereby ensuring that specific values for a system could be included in the initial planning activities.

Values could be identified in an operational concept document, and, for example, a request for quotation, thereby providing information to assist the estimation of effort and resources to develop the system. Requirements that specific values be addressed in the system would appear in a requirements specification, which would ensure that the values to be provided by the system were identified on a contractual basis. Acceptance test cases would be derived from these requirements, so that the 
acquirer could be assured that the required values had been included in the system.

\section{The use of VSD in practice}

From personal observation, many system developers who try to use a method or methodology have an expectation of producing the desired system simply by following a series of documented tasks step by step, and filling in all of the sections of the document templates, regardless of their relevance, or suitability for the work in hand.

Part of their reason for doing this is a lack of understanding of what the method is about, and not knowing how to tailor a "standard' method to suit their particular organisation, product, maturity level, etc. A common example is that of a project plan being prepared because a methodology requires it. This becomes a task, a chore, to get complete and then go on to the interesting work, rather than a useful document being produced for on-going reference and assistance to ensure a successful project. This attitude by the developers could be through a lack of training, or perhaps deeper problems of conceptualisation, and perhaps a reluctance to use any method.

The wording of the ten point approach outlined above implies such a step-wise method. "Point 1 - Start with a Value, Technology, or Context of Use" gives a starting point to the method. However, on further analysis, it may be better to start at point 8 , containing a list of the main values implicated in systems design, and then apply the other points, generally in order, but more iteratively than in strict order. Or it may be better to consider stakeholders first (Point 2), or choose another appropriate starting point related to the particular stage in the life cycle.

This is not to criticise Friedman et al. They are clear about the iterative and flexible approach of VSD. However, the likelihood of developers adopting a new method, VSD, is probably quite low, given their reluctance to use traditional developments methods which have been available to them for over 30 years.

Also, discussion is needed about the level of education and training, in ethics and values, that should be provided before VSD can be used, even in a limited way, by system developers. Such discussion is beyond the scope of this paper.

Point 2 refers to the task of identification of stakeholders, in the categories of direct and indirect. This is not an easy task, and the paper by Bowern et al (2004) discusses issues related to stakeholders, especially that of identification. The paper also identifies some artefacts to support this task. These include the international standard ISO 15288: Life Cycle Management - System life Cycle Processes, which includes a clause on a Stakeholder Requirements Definition Process, and the work by Gotterbarn (eg. 2001) on software development impact statements (SoDIS) and the associated tool to support stakeholder and risk analysis, with an ethical dimension. Also, a very recent paper by Alexander (2005) provides an excellent model and taxonomy for the identification of stakeholders and their requirements.

\section{VSD and electronic voting systems}

Friedman et al (2003) list a number of human values with ethical import which could be considered in relation to 
information systems. The main values that could apply to voting systems are shown below, with Friedman's definitions shown in italics. (Some people may disagree with some of these definitions.) Preliminary comments on how each value could relate to an electronic voting system are also included.

\section{Ownership and Property}

Refers to a right to possess an object (or information), use it, manage it, derive income from it, and bequeath it.

The protection of intellectual property has been an issue in the recent events in the USA, where companies have been reluctant to make their products, particularly their software, open to full inspection. However, it is difficult for citizens to have faith in a product that has not been independently inspected and verified, to ensure that it will produce a fair and accurate result, i.e. one that is not corrupted.

\section{Freedom From Bias}

Refers to systematic unfairness perpetrated on individuals or groups, including preexisting social bias, technical bias, and emergent social bias.

All aspects of voting systems and processes must be politically neutral. Of course, election officials and polling workers, as citizens, will have political preferences, but this must not interfere with their official roles. Possibly the greatest threat of bias is from the suppliers of the voting hardware and software. With closed systems and limited auditing, the chances of detecting corruption in electronic voting systems is low. This is why open standards, open systems, and independent testing and auditing is so important.

\section{Accountability}

Refers to the properties that ensures that the actions of a person, people, or institution may be traced uniquely to the person, people, or institution.

The professionalism of the development and sales staff of the organisations producing voting systems should be at the highest level, to ensure that sound processes exist and are followed. This is one way that citizens can confirm their trust in the developers.

\section{Identity}

Refers to people's understanding of who they are over time, embracing both continuity and discontinuity over time.

Identity management is important, to ensure that each citizen only votes once, and the vote is cast for the correct electorate. This will involve: voter registration to include that person on an electoral role; the maintenance of that electoral roll to ensure that it is up to date and accurate; and its security to protect it from corruption.

\section{Anonymity}

Refers to the absence of identifying information associated with the interaction.

This is a critical value to support the concept of a secret ballot, and it is allied to the value of identity. There must be absolute separation between 
the vote cast by a citizen and any information kept about that citizen in the voter registration and electoral roll systems.

\section{Privacy}

Refers to a claim, an entitlement, or a right of an individual to determine what information about himself or herself can be communicated to others.

Every voter has the right to vote cast a ballot in private, without any coercion. Attendance at an official polling station is the main way that this is achieved. The designers of the voting systems of the future, in which the Internet will be used, will have a great challenge to ensure that voters will have a satisfactory level of privacy when casting their vote.

This value is related to that following, on usability. Electronic voting systems can enable blind voters to cast their ballots in private, through the use of an audio feature, for example.

\section{Universal Usability}

Refers to making all people successful users of information technology.

This value relates to matters of equity and access in the use of technology. The use of voting machines for blind people was mentioned above, but it should be noted that some machines are preferable to others. For example, the blind voters in Canberra do not support the use of touch screen devices. The use of an audio feature for blind people can also provide easier voting for other people, such as those with poor reading ability.
This type of voting technology can also be used to help migrant voters who may have difficulty in understanding the language of their adopted country. Instructions for voting can be provided in many languages, and the audio feature would be of use here too.

\section{Informed Consent}

Refers to garnering people's agreement, encompassing criteria of disclosure and comprehension (for "informed") and voluntariness, competence, and agreement (for "consent").

There are aspects of electronic voting systems which may use techniques which require consent from the users of the system. For example, all of the keystrokes made by a voter may be recorded to provide back up and recovery functions, and as a check to see if the final vote is different from the intentions of the voter. Should voters be aware that their keystrokes are being recorded, and should they be given the opportunity to agree to this?

\section{Conclusion}

In the paper on VSD and information systems (Friedman et al, 2003) the definition of trust refers to expectations that exist between people who can experience good will, extend good will toward others, feel vulnerable, and experience betrayal. Trust could be considered as an overarching value, and the other values listed above also have a component of trust associated with them.

A theme of this paper has been to discuss the lack of trust by citizens in their election systems and technology, and therefore, 
there is a lack of trust in the people who develop and operate those systems. This applies not only to the technology aspects of voting, but also all of the other processes covering acquisition of the technology and the running of elections.

VSD provides a way to identify the human values to be considered by developers of any system, and would be used in conjunction with other development methods and tools. It provides a flexible approach, and attempts to identify the requirements and values of all people who may be affected by the system, directly and indirectly.

The adoption of VSD for the development and implementation of voting systems, electronic or otherwise, could help to promote the trust of citizens in the developers of those systems. This paper is a small start in the work to promote the use of VSD in the development of voting systems.

\section{References}

ACTEC 2004a. ACT Electoral Commission web site, viewed on 3 December, 2004, http://www.elections.act.gov.au/har e.html

ACTEC 2004b. ACT Electoral Commission web site, viewed on 3 December 2004, http://www.elections.act.gov.au/Fac tBP.html

Alexander, I.F. 2005. 'A Taxonomy of Stakeholders: Human Roles in System Development'. International Journal of Technology and Human Interaction, 1(1) January-March.
Bowern M. McDonald C. and Weckert J. 2004. Stakeholder Theory in Practice: Building Better Software Systems, Paper presented at the computer ethics conference ETHICOMP 2004, Syros, Greece, April.

Carter, J. 2004. 'Still Seeking a Fair Florida Vote', Washington Post, Monday, September 27, viewed on 2 December 2004, http://www.washingtonpost.com/wpd yn/articles/A52800 2004Sep26.html

Friedman, B. Kahn Jr P. H. and Howe D. C. 2000. Trust Online. Communications of the ACM, 43(12).

Friedman, B. Kahn Jr P. H. and Borning A. 2003. 'Value Sensitive Design and Information Systems'. In Zhang, P. and Galletta D., (eds). HumanComputer Interaction in Management Information Systems: Foundations. New York: M.E.Sharpe Inc.; Forthcoming.

Gotterbarn, D. 2001. Reducing Software Failures: Addressing the Ethical Risks of the Software Development Lifecycle, a Keynote presentation at ETHICOMP 2001, Gdansk, Poland.

Kennedy School of Government, Harvard University0 2004. 'Electronic Voting Best Practices: A Summary', in a report from the Voting, Vote Capture \&Vote Counting Symposium, June.

Miller, S. 2004. 'Electronic Voting Machines Add Uncertainty to Close Election race'. CorpWatch, 8 September, 2004, http://www.corpwatch.org/article.ph $\mathrm{p} ? \mathrm{id}=11518$ 
Selker, T. 2004. 'Fixing the Vote'. Scientific American, October, 291(4).

Verified Voting Foundation. 2004.

http://www.verifiedvoting.org/ 